\title{
A Comparative Study of Transvaginal Cervical Length at 11-14 Weeks and at 18-22 Weeks of Gestation for the Outcome of Pregnancy
}

\author{
Sonam Chaudhary ${ }^{1}$, Seema Sharma², Swati Garg ${ }^{3}$
}

\begin{abstract}
Background: Spontaneous preterm birth (SPTB) represents a major cause of neonatal morbidity and mortality worldwide. Transvaginal cervical shortening is a predictor of preterm birth. Prediction of preterm labor by measurement of cervical length through transvaginal sonography when coupled with appropriate preterm birth prevention strategies, has been associated with reductions in SPTB in asymptomatic singleton pregnant women.

Materials and methods: This prospective observational study was conducted on 210 pregnant women attending the ANC OPD in the department of Obstetrics and Gynaecology, Mahatma Gandhi Medical College Jaipur, during the time period of January 2017 to June 2018 and fulfilling the inclusion and exclusion criterion for the study. Detailed history taking and pre-evaluation done as per prestructured proforma followed by transvaginal ultrasonography with GE VOLUSON 730 PRO TVS probe IC 5-9 H instrument with 5-9 MHz which was done by a single operator after taking consent. Cervical length was measured at 11-14 weeks and subsequently, the subjects were followed up between 18 weeks and 22 weeks for the repeat readings. Statistical analysis was done to determine the significance of cervical length in predicting preterm labor. The analysis was done using SPSS version 20 (IBM SPSS Statistics Inc., Chicago, Illinois, USA) Windows software program.

Results: In our study, 180 patients had a significant correlation of cervical length at 11-14 and 18-22 weeks in relation to preterm and term delivery. The mean cervical length of the study group at 18-22 weeks was $3.14 \mathrm{~mm}$.

Conclusion: Transvaginal ultrasonographic measurement of cervical length is an effective tool for the evaluation of preterm delivery risk.

Keywords: Ectopic pregnancy, Gestation, Transvaginal.

Journal of Mahatma Gandhi University of Medical Sciences \& Technology (2020): 10.5005/jp-journals-10057-0137
\end{abstract}

\section{INTRODUCTION}

The World Health Organization (WHO) defines preterm birth as, any birth before 37 completed weeks of gestation, or fewer than 259 days since the first day of the woman's last menstrual period (LMP). This is further subdivided based on gestational age (GA):

- Extremely preterm ( $<28$ weeks).

- Very preterm (28 to $<32$ weeks).

- Moderate and late preterm (32 to $<37$ completed weeks of gestation).

This is the most extensively used and accepted definition of preterm birth. ${ }^{1}$

Preterm birth is a global problem in the present era as its occurrence is $>60 \%$ in Africa and South Asia. The rate of preterm birth is $12 \%$ in developing countries as compared to $9 \%$ in developed countries. Within countries, lower socioeconomic status is at higher risk.

The greatest number of preterm births is in India: 3,519,100 2 per annum.

Preterm labor is the major cause of preterm birth that affects $12-18 \%$ of all birth in India.,

Preterm birth is one of the leading causes of perinatal mortality and morbidity. ${ }^{5-9}$ Preterm births are responsible for immediate fetal complications like apnea, respiratory distress syndrome (RDS), intraventricular hemorrhage (IVH), necrotizing enterocolitis (NEC), jaundice, anemia, infections, and also long-term adverse
${ }^{1-3}$ Department of Obstetrics and Gynaecology, Mahatma Gandhi Medical College and Hospital, Jaipur, Rajasthan, India

Corresponding Author: Seema Sharma, Department of Obstetrics and Gynaecology, Mahatma Gandhi Medical College and Hospital, Jaipur, Rajasthan, India, Phone: +91 8696949150, e-mail: drseemadsharma@ gmail.com

How to cite this article: Chaudhary S, Sharma S, Garg S. A Comparative Study of Transvaginal Cervical Length at 11-14 Weeks and at 18-22 Weeks of Gestation for the Outcome of Pregnancy. J Mahatma Gandhi Univ Med Sci Tech 2020;5(3):83-87.

Source of support: Nil

Conflict of interest: None

developmental outcomes like cerebral palsy, retinopathy, learning disabilities, etc., which in turn puts an additional economic burden on developing country like ours.

For the prediction of spontaneous preterm labor screening tests are divided into three categories: (i) risk factor assessment, (ii) cervical length measurement, and (iii) biochemical markers.

Cervical length assessment by ultrasound is routinely done in obstetrics. It has been found that a shorter cervix is at higher risk for preterm delivery than women with a long cervix. Women with shorter cervical length are prone to imminent preterm delivery, therefore early management which includes hospitalization or therapy are considered to avoid complications. 
Cervical length screening in women with a history of prior preterm birth is recommended by the American College of Obstetricians and Gynecologists. ${ }^{10-12}$ It remains controversial whether second-trimester cervical length to be used as a universal screening or not without prior preterm birth.

The various methods to evaluate cervical length are transabdominal, translabial, and transvaginal ultrasound. Each of these techniques has its benefits and limitations. Various studies have shown that the transvaginal method is the most reliable. Transvaginal ultrasound is objective, reproducible, and acceptable to patients. The drawback of the transabdominal approach is not the visualization of the cervix in up to $50 \%$ of cases unless the bladder is full, whereas a filling of the bladder significantly increases the length of the cervix. The limitation of the transperineal approach is its inconsistency in correlation with transvaginal and transabdominal measurement and inadequate visualization of the cervix in up to $25 \%$ of cases. Cervical changes (e.g., dilatation of internal cervical OS) are easily appreciated by transvaginal sonography, but not by digital examination. ${ }^{13-15}$

To bring down the preterm birth rates has become a difficult task not only for developing countries but also for developed countries so, in the present scenario, early detection and timely intervention for prevention can reduce fetal morbidity and mortality to some extent. We aim to conduct the present study to have an increased sensitivity of transvaginal sonography by two scans starting early at 11-14 weeks and then repeating at 18-22 weeks of gestation for predictions of preterm labor and early prevention.

\section{Materials and Methods}

This prospective observational study was conducted in the Department of Obstetrics and Gynaecology, Mahatma Gandhi Medical College, Jaipur, in the time period of January 2017 to June 2018. In this time period, 210 pregnant women attending the outpatient department at 11-14 weeks of gestation were selected as per inclusion and exclusion criteria.

\section{Inclusion Criteria}

- Singleton pregnancy.

- Women presenting ANC OPD MGH, at GA 11-14 weeks and willing to continue follow-up till delivery.

- Women with 1 or more spontaneous preterm birth between 14 weeks and 34 weeks.

- More than 2 D\&E procedures because of voluntary abortion.

\section{Exclusion Criteria}

- Multiple pregnancies.

- Women with obstetric complications like PIH, preeclampsia.

- Women with uterine anomalies, previous history of surgery like conization, etc.

- Women with medical complications like DM, HTN, and renal disorders.

Thirty patients were excluded from the study because of:

- Hypertensive disorders: 10.

- GDM: 5.

- Lost to follow-up: 15.

Informed consent was obtained by patients followed by history as per the preformed structured questionnaire. A complete clinical examination was done. Transvaginal ultrasonography with GE VOLUSON 730 PRO TVS probe IC 5-9 H instrument with 5-9 MHz was done by a single operator after taking consent. Cervical length was measured at 11-14 weeks and subsequently, the subjects were followed up between 18 weeks and 22 weeks for the repeat readings.

A standard longitudinal view of the cervix with an empty bladder was obtained. The cervical length was measured between the internal OS and external OS. The probe was slowly withdrawn until a blurred image is seen. The probe was then inserted again until the image is clear. Fifty to seventy percent of the screen should be occupied by the cervix.

Sometimes cervical glands also help in determining the total length of the cervical canal. In some case, cervix was curved so, two end to end straight measurements or curved cervical length was taken to obtain an accurate length of the cervix. There should be an equal distance of the cervical canal from the anterior and posterior wall of the cervix. For accuracy at least three cervical length measurements were obtained; the shortest and the best measurement were recorded. Cervical length was measured by keeping the probe $3 \mathrm{~cm}$ away from the posterior fornix.

\section{Statistical Analysis}

After recording the data from all the cases, statistical analysis was done to determine the significance of cervical length in predicting preterm labor. The data were coded and entered into a Microsoft Excel spreadsheet. The analysis was done using SPSS version 20 (IBM SPSS Statistics Inc., Chicago, Illinois, USA) Windows software program. Descriptive statistics included the computation of percentages, means, and standard deviations. The independent $t$-test (for quantitative data within two groups) was used for quantitative data comparison of all clinical indicators. Chi-square/ Fisher's exact test was used for qualitative data whenever two or more than two groups were used to compare. The level of significance was set at $p \leq 0.05$.

\section{Results}

In this study, 180 patients were included, mean age \pm SD $=25.73$ \pm 3.86 years. Maximum patients were in the $24-29$ years of age group. Mean married life \pm SD $=3.45 \pm 1.69$ years. According to obstetrical history, among 180 patients, $43.9 \%$ are primigravida and 56 patients have a history of abortion, patients with abortion are included as high risk in our study. $19.4 \%$ have a history of one spontaneous/induced abortion. Whereas $1.7 \%$ have a history of four abortions (Fig. 1).

In our study, 180 patients showed a significant correlation of cervical length at 11-14 weeks and 18-22 weeks in relation to preterm and term delivery. Twenty-eight patients delivered preterm, before 37 weeks and 152 delivered after 37 weeks. $15.5 \%$ of the study group delivered preterm, 6 were before 28 weeks. Ten patients delivered between 28 weeks and 32 weeks and 12 between 32 weeks and 37 weeks (Fig. 2).

This table showed the relationship of cervical length with gestation age at birth, 27 patients delivered before 37 weeks of gestation and rest after 37 weeks (Tables 1 to 4 and Figs 3 and 4).

The cervical length of 180 patients at 18-22 weeks was assessed and there was an association to GA at delivery was observed, 152 patients delivered at term and 28 preterms, the mean cervical length of the study group at 18-22 weeks was 3.14. 


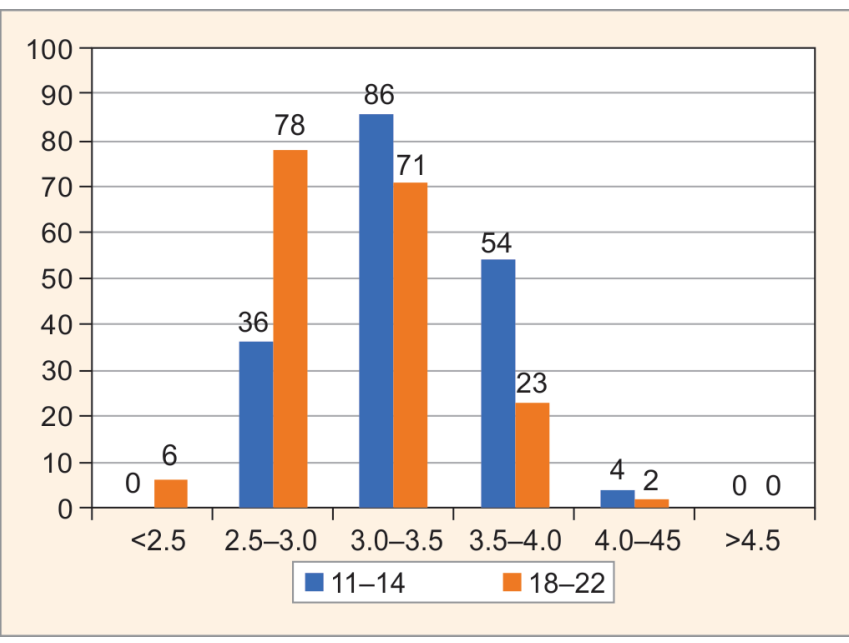

Fig. 1: Cervical length distribution of patients studied

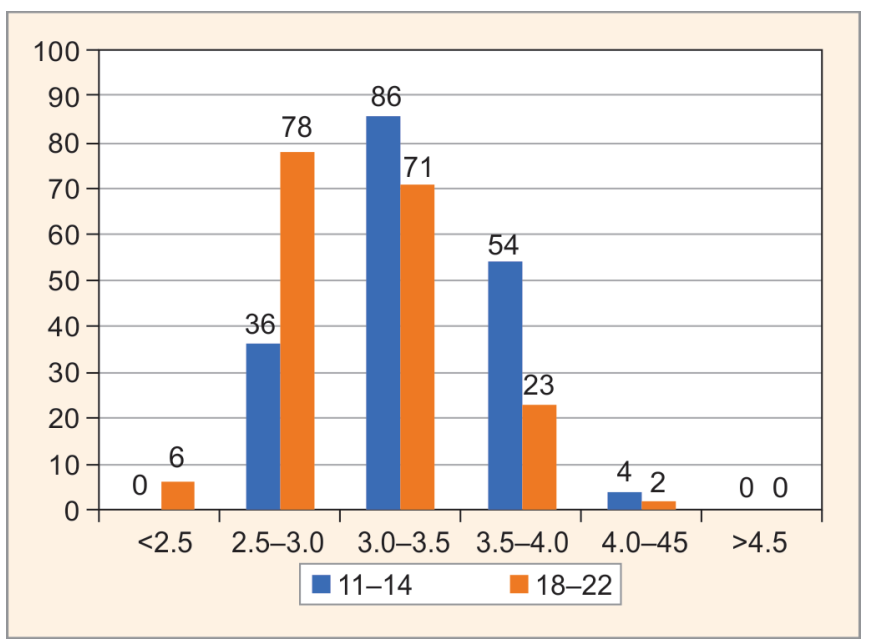

Fig. 2: Correlation of cervical length at 11-14 and 18-22 weeks in relation to preterm and term delivery of patients studied

Table 1: Cervical length distribution of patients studied

\begin{tabular}{llccc}
\hline & In cm & Frequency & Percent & Mean \pm SD \\
\hline 11-14 weeks & $<2.5$ & 0 & 0 & $3.41 \pm 0.35$ \\
& $2.5-3$ & 36 & 20 & \\
& $3-3.5$ & 86 & 47.8 & \\
& $3.5-4$ & 54 & 30 & \\
$18-22$ weeks & $4-4.5$ & 4 & 2.2 & \\
& $>4.5$ & 0 & 0 & $3.14 \pm 0.37$ \\
& $<2.5$ & 6 & 3.3 & \\
& $2.5-3$ & 78 & 39.4 & \\
& $3-3.5$ & 71 & 12.8 & \\
& $3.5-4$ & 23 & 1.1 & \\
& $4-4.5$ & 2 & 0 & \\
& $>4.5$ & 0 & &
\end{tabular}

Table 2: Correlation of cervical length at 11-14 and 18-22 weeks in relation to preterm and term delivery of patients studied

\begin{tabular}{|c|c|c|c|c|c|}
\hline & & Preterm & Term & Total & $X^{2} / p$ value \\
\hline \multirow[t]{6}{*}{$11-14$} & $<2.5$ & 0 & 0 & 0 & $80.92 /<0.001(S)$ \\
\hline & $2.5-3$ & 23 & 13 & 36 & \\
\hline & $3-3.5$ & 5 & 81 & 86 & \\
\hline & $3.5-4$ & 0 & 54 & 54 & \\
\hline & $4-4.5$ & 0 & 4 & 4 & \\
\hline & $>4.5$ & 0 & 0 & 0 & \\
\hline \multirow[t]{6}{*}{$18-22$} & $<2.5$ & 6 & 0 & 6 & $59.75 /<0.001(S)$ \\
\hline & $2.5-3$ & 22 & 56 & 78 & \\
\hline & $3-3.5$ & 0 & 71 & 71 & \\
\hline & $3.5-4$ & 0 & 23 & 23 & \\
\hline & $4-4.5$ & 0 & 2 & 2 & \\
\hline & $>4.5$ & 0 & 0 & 0 & \\
\hline
\end{tabular}

\section{Discussion}

Prediction of preterm labor has been a challenging issue for the last 3-4 decades. Preterm birth is the major cause of perinatal morbidity and mortality in developed countries also. ${ }^{6}$ There are many risk scoring system but still no reduction in preterm births has been found. Risk factor scoring systems have been found to give vague predictions. To predict the cervical changes culminating in preterm labor has remained a tough nut to crack. In such situations, ultrasonographic assessment of cervical length may provide an effective non-invasive method of help. Aderson et al. ${ }^{16}$ first introduce endovaginal ultrasound to predict preterm birth by a cervical length measurement. 
Table 3: Correlation of gestational age at birth at 11-14 and 18-22 weeks in relation to preterm and term of patients studied

\begin{tabular}{|c|c|c|c|c|c|}
\hline & \multirow{2}{*}{$\begin{array}{l}\text { Cervical length } \\
\mathrm{cm}\end{array}$} & \multicolumn{2}{|c|}{ Gestational age at birth } & \multirow[b]{2}{*}{ Total } & \multirow[b]{2}{*}{$X^{2} / p$ value } \\
\hline & & $<37$ weeks & $>37$ weeks & & \\
\hline \multirow[t]{6}{*}{ 11-14 weeks } & $<2.5$ & 0 & 0 & 0 & $75.96 /<0.001(S)$ \\
\hline & $2.5-3$ & 22 & 14 & 36 & \\
\hline & $3-3.5$ & 5 & 81 & 86 & \\
\hline & $3.5-4$ & 0 & 54 & 54 & \\
\hline & $4-4.5$ & 0 & 5 & 4 & \\
\hline & $>4.5$ & 0 & 0 & 0 & \\
\hline \multirow[t]{6}{*}{ 18-22 weeks } & $<2.5$ & 6 & 0 & 6 & $59.63 /<0.001(S)$ \\
\hline & $2.5-3$ & 21 & 57 & 78 & \\
\hline & $3-3.5$ & 0 & 71 & 71 & \\
\hline & $3.5-4$ & 0 & 23 & 23 & \\
\hline & $4-4.5$ & 0 & 2 & 2 & \\
\hline & $>4.5$ & 0 & 0 & 0 & \\
\hline
\end{tabular}

Table 4: Comparison of cervical length $(\mathrm{cm})$ according to preterm/term

\begin{tabular}{llllll}
\hline & & $N$ & Mean $\pm S D$ & Total & pvalue \\
\hline $11-14$ weeks & Term & 152 & $3.49 \pm 0.32$ & $3.41 \pm 0.35$ & $<0.001(\mathrm{~S})$ \\
& Preterm & 28 & $2.98 \pm 0.15$ & & \\
$18-22$ weeks & Term & 152 & $3.23 \pm 0.33$ & $3.14 \pm 0.37$ & $<0.001$ (S) \\
& Preterm & 28 & $2.66 \pm 0.17$ & & \\
\hline
\end{tabular}

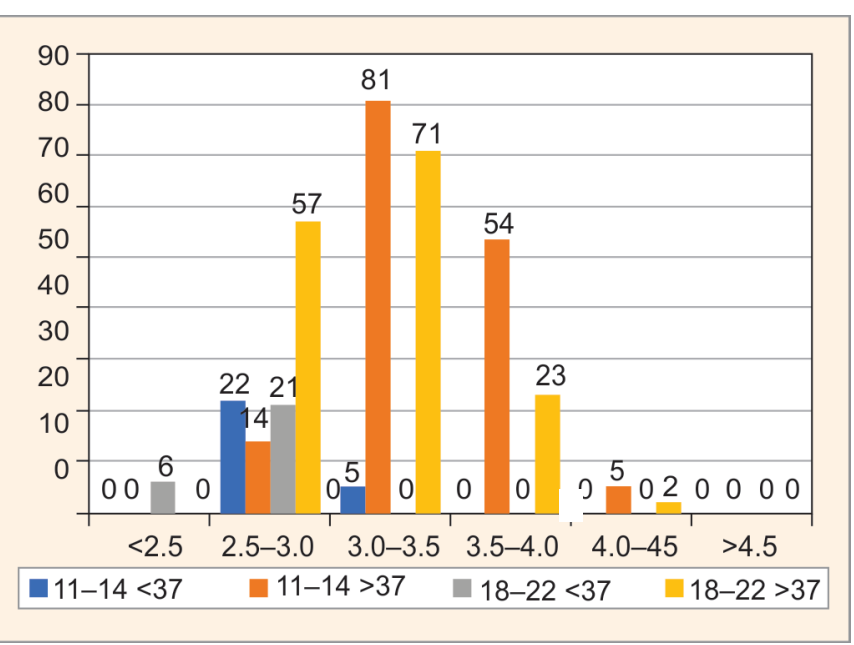

Fig. 3: Correlation of gestational age at birth at 11-14 and 18-22 weeks in relation to preterm and term of patients studied

At 18-22 weeks, transvaginal sonography is economical and trustworthy screening procedure in both low- and high-risk subjects. There were so many studies that provide data regarding cervical assessment through sonography and prediction of preterm labor. lams et al. ${ }^{17}$ had given cutoff values of cervical length and period of gestation which was $<25 \mathrm{~mm}$ at 24 weeks.

The majority of subjects were from 18 to 29 years age groups, i.e., $81.7 \%$. Kore et al. ${ }^{18}$ were recorded in the age group of $20-30$ years. The mean age of the subjects studied was 26 years in this study. Eighteen years of age was the minimum and 39 years of age was the maximum age limit in our study. Moroz and Simhan ${ }^{19}$ were supported our study with a mean age was 23 years.

In this study, the minimum cervical length measured was 2.1 $\mathrm{cm}$ and the maximum cervical length measured was $4.4 \mathrm{~cm}$. In the study supported by Arora et al., ${ }^{20}$ the mean cervical length was

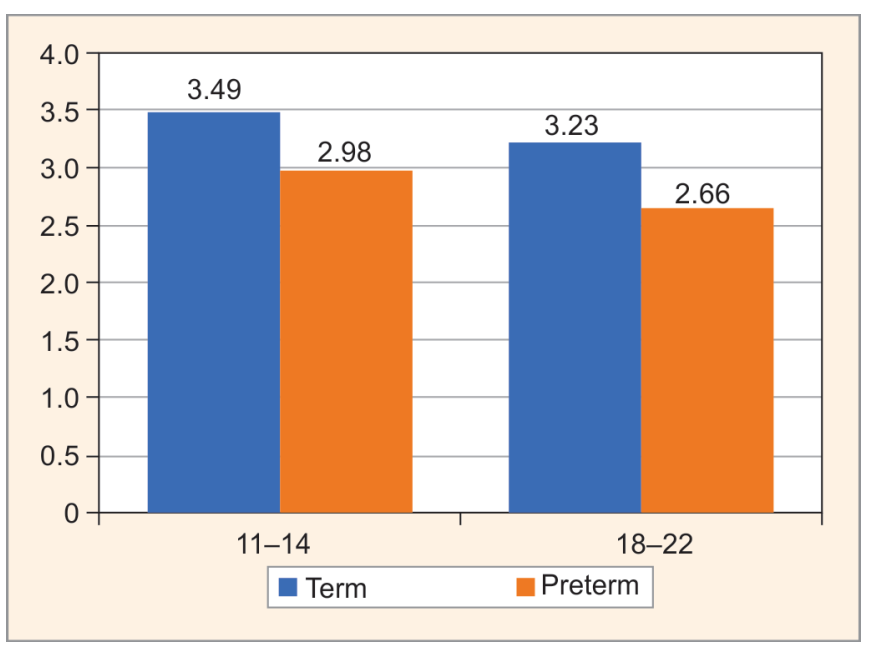

Fig. 4: Comparison of cervical length $(\mathrm{cm})$ according to preterm/term

$3.2 \mathrm{~cm}$ with a minimum measurement of $2.1 \mathrm{~cm}$ and maximum measurement of $4.4 \mathrm{~cm}$. In similar studies conducted by lams et al. ${ }^{17}$ and Hebbar and Samjhana, ${ }^{21}$ the mean cervical length was $3.5 \mathrm{~cm}$.

In the present study, mean cervical length in the study population was $3.41 \mathrm{~mm}$ at $11-14$ week and $3.14 \mathrm{~mm}$ at $18-22$ which was related to study results of lams et al. ${ }^{17}$ and almost correlated to results of Kore et al. $^{22}$

Among those with a cervical length of $\leq 2.5 \mathrm{~cm}$, term delivery occurred in none of the women, whereas only 6 women delivered preterm. Among those with a cervical length of $3-3.5 \mathrm{~cm}$, preterm delivery in 5 of women among 11-14 weeks, whereas 81 (11-14 weeks) and 71 (18-22 weeks) delivered full term. This study showed statistically significant results. Therefore, a minimum value of $\leq 2.5$ $\mathrm{cm}$ cervical length is a better predictor of preterm delivery. Whereas in similar studies by Hebbar and Samjhana ${ }^{21}$ used a cutoff value of $\leq 25 \mathrm{~mm}$, lams et al. ${ }^{17}$ used a cutoff value of $\leq 25 \mathrm{~mm}$ and Taipale 
and Hiilesmaa ${ }^{23}$ used a cutoff value of $\leq 25 \mathrm{~mm}$. In similar studies, Arora et al. used a cutoff value of $\leq 30 \mathrm{~mm} .^{20}$

The study reports that transvaginal sonography can be used to measure maternal cervical length during pregnancy to predict the risk of preterm delivery. The cervical length difference at 11-14 weeks for those who delivered at term and those who delivered preterms was not statistically significant. The cervical length at 18-22 weeks in the group that delivered preterm was significantly shorter than in those who had delivered at term. The mean cervical showed a gradual decrease from the first to the second scan, and increased risk for preterm delivery was seen in those cases which demonstrated a rapid shortening in cervical length.

We found that cervical length was shorter in women aged $<25$ years. This is compatible with the well-documented increased risk for poorer pregnancy outcomes in teenagers. It has previously been recommended that the increased risk might be due to associated social and behavioral factors rather than intrinsic biological determinants of the young age. ${ }^{24}$

The findings confirm with those of previous studies which have shown an inverse relationship between the length of the cervix and duration of pregnancy. These data suggest that the duration of pregnancy is directly correlated to the length of the cervix measured using a transvaginal scan with strict criteria and a short cervix has a greater association with preterm labor.

Our findings confirm these of the previous studies that have found an increased relationship between the length of the cervix and preterm delivery. Vaginal ultrasound produced better images in the study. Although the predictive value was low in the low-risk population, it will increase the risk of prematurity in the population studies. This method can be used to select patients for prospective interventional trials with the rationale that early intervention might be more effective. Transvaginal ultrasonography can also be used in combination with other markers for preterm delivery such as fetal fibronectin, serum alpha-fetoprotein, serum alkaline phosphatase, in developing treatment strategies.

There are few longitudinal studies of cervical assessment in the literature as a screening test for preterm delivery. Further studies should be undertaken to establish whether the best management procedure for screening for prematurity is a single examination in the second trimester or follow-up scans from the first trimester of pregnancy. Variation in results of the present study and other studies might be due to racial and ethnic factors.

\section{Conclusion}

Transvaginal ultrasonographic measurement of cervical length was better than transabdominal ultrasound for evaluation of preterm delivery risk. Cervical length was decreased in women with singleton pregnancy to high-risk pregnancies, therefore cervical length was useful for the prediction of preterm delivery.

\section{References}

1. Howson CP, Kinney MV, Lawn J, March of Dimes, PMNCH, Save the Children, WHO; 2012. Born Too Soon: the global action report on preterm birth.

2. http://www.who.int/news-room/fact-sheets/detail/preterm-birth.

3. Blencowe $\mathrm{H}$, Cousens $\mathrm{S}$, Oestergaard MZ, et al. National, regional and worldwide estimates of preterm birthrates in the year 2010 with time trends since 1990 for selected countries: a systematic analysis and implications. Lancet 2012;379(9832):2162-2172. DOI: 10.1016/ S0140-6736(12)60820-4.
4. Beck S, Wojdyla D, Say L, et al. The worldwide incidence of preterm birth: a systematic review of maternal mortality and morbidity. Bill World Health Organ 2010;88(1):31-38. DOI: 10.2471/BLT.08.062554.

5. Alexander GR, Kogan M, Bader D, et al. US birth weight/gestational age-specific neonatal mortality: 1995-1997 rates for whites, hispanics, and blacks. Pediatrics 2003;111(1):e61-e66. DOI: 10.1542/ peds.111.1.e61.

6. Behrman RE, Butler AS, Preterm birth: causes, consequences, and prevention. National Academies Press: Committee on Understanding Premature Birth and Assuring Healthy Outcomes, Board on Health Sciences Policy, Institute of Medicine of the National Academies; 2007.

7. Lawn JE, Cousens S, Zupan J. 4 Million neonatal deaths: When? where? why? Lancet 2005;365(9462):891-900. DOI: 10.1016/S01406736(05)71048-5.

8. McCormick MC. The contribution of low birth weight to infant mortality and childhood morbidity. N Engl J Med 1985;312(2):82-90. DOI: 10.1056/NEJM198501103120204.

9. Berkowitz GS, Papiernik E. Epidemiology of preterm birth. Epidemiol Rev 1993;15(2):414-443. DOI: 10.1093/oxfordjournals.epirev. a036128.

10. Schaaf JM, Hof MF, Mol B, et al. Recurrence risk of preterm birth in subsequent twin pregnancy after preterm singleton delivery. BJOG 2012;119(13):1624-1629. DOI: 10.1111/j.1471-0528.2012.03504.x.

11. Khandelwal M. Vaginal progesterone in risk reduction of preterm birth in women with short cervix in the mid trimester of pregnancy. Int J Womens Health 2012;4:481-490. DOI: 10.2147/IJWH.S28944.

12. American College of Obstetricians and Gynecologists. Prediction and prevention of preterm birth. Practice bulletin no. 130. Obstet Gynaecol 2012;120:964-967.

13. Okitsu O, Mimura T, Nakayama T, et al. Early prediction of preterm delivery by transvaginal ultrasonography. Ultrasound Obstet Gynecol 1992;2(6):402-409. DOI: 10.1046/j.1469-0705.1992.02060402.x.

14. Berghella V, Tolosa JE, Kuhlman K, et al. Cervical ultrasonography compared with manual examination as a predictor of preterm delivery. Am J Obstet Gynecol 1997;177(4):723-730. DOI: 10.1016/ S0002-9378(97)70259-X.

15. To MS, Skentou C, Chan C, et al. Cervical assessment at the routine 23-week scan: standardizing techniques. Ultrasound Obstet Gynecol 2001;17(3):217-219. DOI: 10.1046/j.1469-0705.2001.00369.x.

16. Andersen HF, Nugent $C E$, Wanty SD, et al. Prediction of risk for preterm delivery by ultrasonographic measurement of cervical length. Am J Obstet Gynecol 1990;163(3):859-867..

17. lams JD, Goldenberg RL, Meis PJ, et al. The length of the cervix and the risk of spontaneous premature delivery. National Institute of Child Health and Human Development Maternal Fetal Medicine Unit Network. N Engl J Med 1996;334(9):567-572. DOI: 10.1056/ NEJM199602293340904.

18. Kore SJ, Rao S, IBhagwat A, et al. Prediction of preterm labour by transvaginal sonography. Bombay Hospital J 2004;46(3).

19. Moroz LA, Simhan HN. Rate of sonographic cervical shortening and the risk of spontaneous preterm birth. Am J Obstet Gynec 2012;206(3):234.e1-5. DOI: 10.1016/j.ajog.2011.11.017.

20. Arora P, Maitra NK, Agarwal S. Cervical length measurement by transvaginal ultrasound at 20-24 weeks gestation and the timing and mode of delivery. J South Asian Feder Obst Gynae 2012;4(1):22-24. DOI: 10.5005/jp-journals-10006-1165.

21. Hebbar S, Samjhana K. Role of mid-trimester transvaginal cervical ultrasound in prediction of preterm delivery. Med J Malaysia 2006;61(3):307-311.

22. Kore SJ, Parikh MP, Lakhotia S, et al. Preduction of risk of preterm delivery by cervical assessment by transvaginal ultrasonography. J Obstet Gynecol India 2009;59(2):131-135.

23. Taipale $\mathrm{P}$, Hiilesmaa V. Sonographic measurement of uterine cervix at 18-22 weeks' gestation and the risk of preterm delivery. Obstet Gynecol 1998;92(6):902-907. DOI: 10.1016/S0029-7844(98)00346-9.

24. Zuckerman BS, Walker DK, Frank DA, et al. Adolescent pregnancy: biobehavioural determinants of outcome. J Pediatr 1984;105(6):857862. DOI: 10.1016/S0022-3476(84)80066-9. 